\title{
Determination of Diphenylamine in Powder by Pure Diphenylamine as External Standard Substance
}

\author{
Bin ZHANG ${ }^{1}$, Xiao-yu $\mathrm{LI}^{2}$, Ran XIONG ${ }^{3, a}$ \\ ${ }^{1}$ No. 63981 Unit of PLA, 430311, China \\ ${ }^{2}$ No. 63981 Unit of PLA, 430311 China \\ ${ }^{3}$ No. 63981 Unit of PLA, 430311, China \\ aemail: Bxiongran@163.com
}

Keywords: Gas chromatography; Powder; Diphenylamine; External standard method

\begin{abstract}
The content of diphenylamine in standard powder is determined by pure diphenylamine as external standard substance in this paper, the value of relative deviation is in the range of $\pm 3 \%$. The method was applied to the analysis of samples of powder, the vales of RSD $(n=6)$ were found to less than $3 \%$, and the results obtained were in conformity with those by standard powder method .The method has compensated the shortcomings by the standard powder as external standard substance. The method has showed the features of simple and rapid in operation, good in safety, and high in precision and accuracy.
\end{abstract}

\section{Introduction}

Double-base powder is mainly composed of nitrocellulose, nitroglycerin, diphenylamine (dimethyldiphenylurea) and specific solvents, etc. Diphenylamine can reduce the production of the acidity oxidation decomposition, and prevent the accelerated decomposition of nitrate esters, thus the powder has a relatively stable chemical stability in the process of long-term storage. So the accurate determination of the content of diphenylamine in powder is very important.

Gas chromatography is mainly used to the determination of diphenylamine in the powder for many years, the external standard was developed by authority standard powder. But these standards powder has a regulation of use fixed years (usually 5 10years), the content of diphenylamine in the standard powder will change within the prescribed period, that affected the accuracy of test results; Also the external standard need to be purchased after the rules of use fixed years, while the standard powder is dangerous goods, and the transportation is very troublesome. Therefore, to find another material as the external standard to replace the current standard powder was necessary. It's obtained that the pure diphenylamine as external standard substance can instead of standard powder in the determination of diphenylamine in powder through experiment.

\section{Experiment}

\section{Instrument and main reagents}

MODEL SQ-206 GAS CHROMATOGRAPH, SQ-206 thermal conductivity detector, SQ-204 temperature controller(Beijing analysis instrument factory);

Hydrogen (99.999\%): used as a carrier gas;

Acetone and petroleum ether (analytical pure): used for dissolving pure diphenylamine and leaching samples powder;

Pure diphenylamine (99.999\%), 10 batches of flake standard powder (standard diphenylamine 1.32\%), 12 batches of flake standard powder (diphenylamine standard 1.35\%), 10 batches of tubular standard powder (diphenylamine standard 2.79\%), 12 batches of tubular standard powder (diphenylamine standard 2.86\%): used as external standard substance (Using pure diphenylamine calibration, be called pure diphenylamine method for short; Using the standard calibration, and be called standard powder method for short). 


\section{The preparation of experiment samples}

Double-base powder was required to smash except for less than $2 \mathrm{~mm}$ small medicine granule and the pill. The sample which could be scraped should try to be smashed into flower flake or sawdust[4]. The smashed samples should be taken around $2 \mathrm{~g}$ according to accurate to 0.001g, placed in a dry and clean conical flask of $50 \mathrm{ml}$. The $15 \mathrm{ml}$ liquid of volume ratio=4:6(acetone than petroleum ether) was joined with quantitative liquid pipe, and which could be used to measure after the samples soaked by $6 \mathrm{~h}[5]$.

\section{Preparation of standard sample}

Using a standard method of powder, the preparation was same as the 1.2.

When the content of the diphenylamine in powder was below $2.0 \%$, according to get around $0.027 \mathrm{~g}$ of pure diphenylamine with using pure diphenylamine method; If the content of the diphenylamine in powder was more than $2.0 \%$, according to get pure diphenylamine around $0.057 \mathrm{~g}$, the $15 \mathrm{ml}$ liquid of volume ratio=4:6(acetone than petroleum ether) was joined with quantitative liquid pipe, after shaking conical flask to completely dissolved, and the samples could be used for calibration.

\section{The conditions of chromatographic}

Velocity of carrier gas (H2): 130 180ml/min;

Temperature of gasification chamber: $210 \sim 230^{\circ} \mathrm{C}$;

Temperature of hot wire: $195 \sim 205^{\circ} \mathrm{C}$;

Temperature of oven: $165 \sim 180^{\circ} \mathrm{C}$;

Attenuation coefficient: 1;

Stainless steel column: 3mm of inner diameter, 500mm of length.

\section{Analysis method}

After the instrument work, baseline straight, using pure diphenylamine or standard powder to calibrate (If the content of the diphenylamine in powder was under $2.0 \%$, using the shape standard powder; if the content of the diphenylamine in powder was more than $2.0 \%$, using the tubular standard powder), and the sample load be kept by $6 \mathrm{uL}$, and the peak height of diphenylamine was determined by 5 times, which the poor peak height was not more than $5 \%$.

The 6uL leaching liquid was sampled by micro syringe after calibration qualified. The peak height of diphenylamine in sample powder was determined by 2 times with each leaching liquid, which the difference between the peak height was not more than 5\%. Each sample with two copies of leaching liquid, and the average of the determination results of two copies of leaching liquid was no more than $0.2 \%[6]$.

\section{The results and discussion}

\section{Analysis of standard sample powder}

According to the analysis method of the chromatographic conditions 1.4 and 1.5 to use pure diphenylamine method for determination of the content of diphenylamine in standard powder (the content of standard powder and frequently-used powder was same, the method was feasibility as a reference to test pure diphenylamine). the analysis results are shown in Table 1.

We can see from table.1: the results of 2 copies of leaching liquid was no more than $0.2 \%$ for each samples with two copies of leaching liquid, and each leaching liquid measured by 2 times, and the average relative error within $3 \%$. So we can see that the accuracy of the pure diphenylamine method was higher. 
Tab.1 Result of experiment for diphenylamine in standard powder

\begin{tabular}{|c|c|c|c|c|c|c|c|}
\hline \multirow{2}{*}{$\begin{array}{c}\text { standard } \\
\text { sample }\end{array}$} & \multirow{2}{*}{ standard values $\omega / \%$} & \multicolumn{2}{|c|}{ measure values $\omega / \%$} & \multicolumn{3}{|c|}{ average value $\omega / \%$} & \multirow{2}{*}{ error } \\
\cline { 3 - 7 } & & 1 & 2 & 1 & 2 & $1+2$ & \\
\hline 1 & 1.32 & 1.381 .26 & 1.361 .32 & 1.32 & 1.34 & 1.33 & 0.78 \\
\hline 2 & 1.35 & 1.281 .36 & 1.231 .37 & 1.32 & 1.30 & 1.31 & -2.96 \\
\hline 3 & 2.79 & 2.682 .81 & 2.852 .94 & 2.75 & 2.90 & 2.83 & 1.43 \\
\hline 4 & 2.86 & 2.752 .82 & 2.882 .78 & 2.79 & 2.83 & 2.81 & -1.75 \\
\hline
\end{tabular}

\section{Experiment of precision}

Each samples prepared with 6 copies of leaching liquid according to pure diphenylamine method for 5 types of powder each selected, that the each leaching liquid had two parallel determination. The analysis results are shown in table 2.

Tab.2 Results of experiment for precision of the method

\begin{tabular}{|c|c|c|c|c|c|c|c|c|c|}
\hline sample & \multicolumn{6}{|c|}{ measure values $\omega / \%$} & average value $\omega / \%$ & standard deviation $\times 10^{-2}$ & $\mathrm{RSD} / \%$ \\
\hline 1 & 1.34 & 1.35 & 1.39 & 1.38 & 1.41 & 1.37 & 1.37 & 0.03 & 2.19 \\
\hline 2 & 1.59 & 1.62 & 1.68 & 1.66 & 1.64 & 1.69 & 1.65 & 0.04 & 2.42 \\
\hline 3 & 1.93 & 2.08 & 2.04 & 1.99 & 1.96 & 2.05 & 2.01 & 0.06 & 2.99 \\
\hline 4 & 2.26 & 2.29 & 2.37 & 2.31 & 2.41 & 2.32 & 2.33 & 0.05 & 2.14 \\
\hline 5 & 2.75 & 2.90 & 2.82 & 2.78 & 2.84 & 2.93 & 2.84 & 0.07 & 2.46 \\
\hline
\end{tabular}

Table. 2 shows: the parallel sample was measured by 6 times according to analysis method and chromatographic conditions of pure diphenylamine method. The RSD of measure value of each sample was not more than $3 \%$, which shows that the precision of the pure diphenylamine method was higher.

\section{Conclusion}

The content of diphenylamine in all kinds of powder samples was determined by pure diphenylamine method and standard powder method, the results are shown in table.3.

Tab.3 Comparison of analytical results obtained by 2 different methods

\begin{tabular}{|c|c|c|c|c|c|c|}
\hline \multirow{2}{*}{ sample } & \multicolumn{5}{|c|}{ pure diphenylamine method } & \multirow{3}{*}{$\begin{array}{c}\begin{array}{c}\text { standard powder } \\
\text { method }\end{array} \\
\text { measure values } \omega / \% \\
125\end{array}$} \\
\hline & \multicolumn{4}{|c|}{ measure values $\omega / \%$} & average value $\omega / \%$ & \\
\hline 1 & 1.32 & 1.38 & 1.41 & 1.36 & 1.37 & \\
\hline 2 & 1.42 & 1.43 & 1.38 & 1.41 & 1.45 & 1.38 \\
\hline 3 & 1.47 & 1.43 & 1.38 & 1.34 & 1.41 & 1.39 \\
\hline 4 & 1.68 & 1.64 & 1.71 & 1.69 & 1.68 & 1.59 \\
\hline 5 & 1.82 & 1.75 & 1.78 & 1.84 & 1.80 & 1.73 \\
\hline 6 & 2.52 & 2.48 & 2.39 & 2.40 & 2.45 & 2.47 \\
\hline 7 & 2.67 & 2.84 & 2.81 & 2.74 & 2.77 & 2.71 \\
\hline 8 & 2.87 & 2.93 & 2.78 & 2.82 & 2.85 & 2.78 \\
\hline 9 & 2.98 & 2.88 & 2.83 & 2.94 & 2.91 & 2.83 \\
\hline
\end{tabular}

Table. 3 shows: the determination results of pure diphenylamine method and standard powder method were consistent. 


\section{References}

[1] Su Yiren, Chen Shaoliang etc. Physical and chemical analysis of propellant[M], Beijing: National Defence Industry Press, 1999: 343-345.

[2] Xiao Guoshan, LU Guie etc. Test methods for powder[M], Beijing: National Defence Industry Press, 2006: 159-162.

[3] Tao Zhongjin. Chromatography(2)[M], Beijing: Science press, 1986: 74.

[4] GJB535-757 Powder sample attrition[S].

[5] GJB249-680 Double-base power extraction[S]

[6] GJB250-786 Content of diphenylamine of double-base power by gas chromatography[S] 